Karoline Carula

Universidade do Estado do Rio de Janeiro, Rio de Janeiro, RJ, Brasil

\title{
A imprensa feminina no Rio de Janeiro nas décadas finais do século XIX
}

Resumo: O objetivo deste artigo é apresentar e analisar três jornais escritos por mulheres e que circularam na cidade do Rio de Janeiro no final do Oitocentos: O Sexo Feminino (1873-1889) - o qual, após a República passou a se chamar O Quinze de Novembro do Sexo Feminino (18891890) -, Echo das Damas (1879-1888) e A Familia (1888-1894). Com relação ao O Sexo Feminino, seu tema central foi a educação feminina como necessária para o aperfeiçoamento da sociedade. O Echo das Damas teve na defesa da educação feminina seu principal tema. Já em A Familia, as temáticas mais frequentes foram a educação, o trabalho e o voto femininos. Posto isso, incialmente serão apresentadas as três publicações: materialidade, periodicidade, seções, colaboradoras, principais temas abordados, etc. Em seguida, focarei nas principais propostas apresentadas por esses periódicos.

Palavras-chave: imprensa; mulheres; educação feminina.

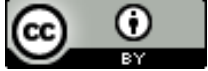

Esta obra está sob licença Creative Commons.

'Marialva BARBOSA, 2010, p. 117.

2 BARBOSA, 2010, p. 118.
Nas últimas décadas do século XIX, a leitura passou a ser um hábito nos centros urbanos, realizada nas "soleiras ou apoiados nos umbrais das portas, debaixo dos postes iluminados, nos bondes nas praças, ruas e avenidas" e também "nos cafés, nos espaços de trabalho, nas salas de visita das casas".' Em tal panorama, sobressai a imprensa periódica. Marialva Barbosa assevera que, nos anos de 1880 , juntamente com os jornais diários, circulavam "[...] revistas mundanas, periódicos críticos e literários, impressos que falam exclusivamente do mundo do trabalho, entre centenas de publicações". ${ }^{2}$ Ou seja, a imprensa tinha um papel de relevo no cotidiano daquelas pessoas. O que nela se noticiava era comentado e discutido em diversos espaços de sociabilidade.

Além de promover a educação por meio de seus artigos mais informativos, as publicações também discutiam a importância da imprensa para a sociedade e o progresso 
${ }^{3}$ BARBOSA, 2010, p. 209.

${ }^{4}$ Mônica Yumi JINZENJI, 2010.

${ }^{5}$ Zahidé Lupinacci MUZART, 2003 p. 226.

${ }^{6}$ A data final, para todos os jornais, é referente ao último número disponível na Biblioteca Nacional não necessariamente a data de encerramento da publicação. ${ }^{7}$ As discussões aqui apresentadas constituem parte dos resultados de uma pesquisa de pós-doutorado desenvolvida na Universidade Federal Fluminense.

${ }^{8}$ Filha de Eduardo Gonçalves da Motta Ramos e Gertrudes Alves de Mello Ramos, Francisca Senhorinha da Motta Diniz nasceu na província de Minas Gerais, na cidade de São João Del Rei. Casou-se com o advogado Dr. José Joaquim da Silva Diniz, que a deixou viúva em 1886. Dedicou-se ao magistério e à imprensa, nesta, além de ter fundado $O$ Sexo Feminino, colaborou em A Estação, foi editora de A Voz da Verdade e A Primavera (Roberta Guimarães TEIXEIRA, 2010, p. 55).

9 Seu primeiro número em Campanha data de sete de setembro de 1873 e o derradeiro exatamente um ano depois totalizando 45 edições. No Rio de Janeiro, o número inicial é de 22 de julho de 1875. O último número existente no acervo da Biblioteca Nacional foi publicado em seis de dezembro de 1890 , quando a publicação já se chamava O Quinze de Novembro do Sexo Feminino. da nação. Jornais e revistas, tanto os direcionados às mulheres quanto os voltados a um público amplo, dedicaram-se a tal causa civilizadora e modernizadora. De acordo com Barbosa, dirigidos ao público feminino, "Afora o folhetim, criam-se outras colunas de moda, de entretenimento, concursos femininos, destinam-lhe artigos e enquetes. Como resposta, as cartas das leitoras inundam as publicações". ${ }^{3}$

Desde o início do Oitocentos, a imprensa periódica se empenhou na causa da educação feminina. Nessa perspectiva, destaco o jornal mineiro O Mentor das Brasileiras, o qual circulou entre 1829 e 1832 veiculando um discurso da elite liberal moderada, que valorizava a educação da mulher como basilar para a construção da nação. ${ }^{4}$ As publicações periódicas destinadas ao público feminino eram escritas essencialmente por homens, o que passou a mudar na segunda metade do século XIX, quando surgiram alguns jornais escritos por mulheres. Cabe destacar, entretanto, que a produção desses periódicos direcionados às mulheres, ainda que escritos por homens, valorizava-as, de alguma forma, na construção da nação.

Conforme afirma Zahidé Lupinacci Muzart, a necessidade da conquista de direitos foi o que motivou as mulheres a fundar e dirigir periódicos. Na pauta de reivindicações estavam, nesta ordem, educação, profissão e voto. Segundo Muzart,

O direito à eucação era, primordialmente, para o casamento, para melhor educar os filhos, mas deveria incluir também o direito de freqüentar escolas, daí decorrendo o direito à profissão. E mais para o final do século, inicia-se a luta pelo voto. O sufragismo foi o mote de luta do feminismo, como todos sabem, e foi também a primeira estratégia formal e ampla para a política das mulheres. ${ }^{5}$

Posto isso, o objetivo do presente artigo é apresentar e analisar três jornais escritos por mulheres e que circularam na cidade do Rio de Janeiro no final do Oitocentos: O Sexo Feminino (1873-1889), que, após a República, passou a se chamar O Quinze de Novembro do Sexo Feminino (18891890), Echo das Damas (1879-1888) e A Familia (18881894). ${ }^{6}$ Inicialmente, farei a apresentação dos três periódicos, destacando: materialidade, periodicidade, seções, colaboradoras, principais temas abordados, etc.; pretendendo, assim, apreender, de maneira mais densa, os impressos em sua multiplicidade de aspectos. ${ }^{7}$

O Sexo Feminino (1873-1889) foi fundado por Francisca Senhorinha da Motta Diniz, que exercia a função de redatora-principal, ${ }^{8}$ sendo publicado inicialmente na cidade mineira de Campanha, onde circulou por um ano, quando foi transferido para a capital imperial. ${ }^{9} \mathrm{O}$ marido 
10 Cecília Vieira do NASCIMENTO e Bernardo J. OLIVEIRA, 2007, p. 434.

"O SEXO FEMININO, 2 abr. 1876 , p. 1.

\footnotetext{
${ }^{12}$ No Rio de Janeiro, em 1875, as missivas para Francisca Diniz deveriam ser direcionadas aos seguintes endereços: Praça da Aclamação, 32 (n. 1-7); Praça do Aclamação, 49 (n. 8-12); R. do Lavradio, 45 ou R. dos Ourives, 9 (n. 13-19); R. do Regente, 32 ou R. dos Ourives, 9 (n. 20-21); R. dos Ourives, 7 (n. 22).

${ }^{13}$ As tipografias foram: Lombaerts \& Filho, R. dos Ourives, 11 (1875, n. 1-11); Americana, R. dos Ourives, 9 (1875-1876, n. 12-22); Machado \& C., R. de Gonçalves Dias, 28 (1889, n. 1-9); Econômica, R. de Gonçalves Dias, 28 (1889, n. 10); Montenegro, R. Nova do Ouvidor, 16 (1889, n 12); Mont'Alverne, R. da Uruguaiana, 43 (1889, n. 13-23)

${ }^{14}$ As redações situavam-se à: $R$. do Lavradio, 101 (n. 1-8); R. do Lavradio, 24 (n. 9-19); R. do Senador Euzebio, 78 (n. 20-23).

${ }^{15}$ Roger CHARTIER, 1996, p. 97.
}

da proprietária, o advogado José Joaquim da Silva Diniz, também era dono de um jornal, O Monarchista, também editado em Campanha. A filiação monarquista de José Diniz se refletiu numa simpatia por esse regime em Francisca Diniz, que a expôs em seu jornal. ${ }^{10}$ No Rio de Janeiro, circulou com esse nome até a proclamação da República, quando mudou para O Quinze de Novembro do Sexo Feminino (18891890), mantendo a mesma sequência de numeração do periódico anterior.

Em 1876, O Sexo Feminino publicou a seguinte nota: "A redatora desta folha, achando-se doente e toda sua família, e ainda mais, aterrada pela epidemia atual, a febre amarela, retira-se por algum tempo para fora da corte, e por esse motivo só mensalmente sairá a folha, até a sua volta". ${ }^{11}$ Após esta edição, a próxima existente no acervo da Biblioteca Nacional é de 1889.

O Sexo Feminino tinha como subtítulo "Semanário dedicado aos interesses da mulher", o qual foi alterado, em 1889, para "Semanário literário, recreativo e noticioso", acrescentando palavras que corroboravam características já presentes no periódico. Quando seu nome foi alterado para O Quinze de Novembro do Sexo Feminino, sua periodicidade mudou para semanal, sendo apresentada no subtítulo: "Periódico quinzenal, literário, recreativo e noticioso. Especialmente dedicado aos interesses da mulher". Manteve esses dizeres até a edição de 16 de julho de 1890 , quando trocou a palavra "periódico" por "revista". Enquanto editado em Campanha, O Sexo Feminino não teve endereço de escritório explicitado, as cartas deveriam ser direcionadas para Francisca Senhorinha da Motta Diniz, e fez uso da tipografia do Monarquista. Ao se estabelecer no Rio de Janeiro, os endereços para correspondência foram vários, ${ }^{12}$ bem como as tipografias. ${ }^{13}$ Somente em 1889, a publicação passou a ter um endereço de redação assim nomeado. ${ }^{14}$

Com relação à quantidade de páginas, ambos os periódicos eram impressos em quatro páginas. Entretanto, houve uma pequena alteração na formatação, O Sexo Feminino possuía duas colunas, conforme se observa na Imagem I, e O Quinze de Novembro do Sexo Feminino tinha três. No tocante à diagramação dos materiais impressos, Roger Chartier adverte que os dispositivos puramente textuais

[...] são cruzadas com outras, trazidas pelas próprias formas tipográficas: a disposição e a divisão do texto, sua tipografia, sua ilustração. Esses procedimentos de produção de livros não pertencem à escrita, mas à impressão, não são decididas pelo autor, mas pelo editor-livreiro e podem sugerir leituras diferentes de um mesmo texto. ${ }^{15}$ 
${ }^{16}$ O Sexo Feminino, 7 set. 1873 , p. 4.

Imagem I: Primeira página da edição inaugural d' O Sexo Feminino na cidade do Rio de Janeiro, 22 de julho de 1875 (Acervo da Fundação Biblioteca Nacional - Brasil).

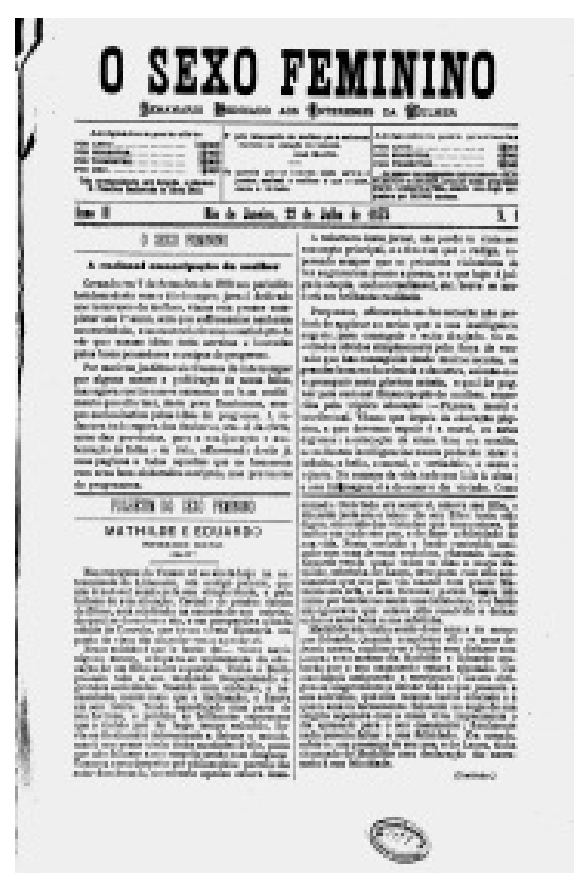

Com o intuito de divulgar a folha, no seu lançamento em Campanha, a redatora enviou exemplares gratuitos para determinadas pessoas e solicitou que, "[...] no caso de não Ihes convir assinar nossa folha, devolvam-na ao escritório da redação". ${ }^{16}$ Exato um ano depois, no último número publicado naquela cidade, Francisca Senhorinha da Motta Diniz destacou:

A tiragem deste hebdomadário era de 800 exemplares, e coisa singular, esta folha não contou com 10 números devolvidos! Neste momento solene, a redatora envia seu reconhecimento aos signatários desta folha, e máxime aos desta tão boa cidade da Campanha. Parece incrível que um humilde periódico de desprezível formato seja lido na velha capital da Espanha na Europa e na soberba Nova lorque dos Estados Unidos, o assombro da moderna civilização, e o modelo invejado do aperfeiçoamento de progresso moral, intelectual e material. Desde o Amazonas até os confins do Rio Grande do Sul é esta folha conhecida, e ainda agora choviam os pedidos de números editados e novas

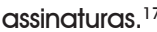

${ }^{17}$ ANIVERSÁRIO DO PERIÓDICO O Sexo Feminino, 7 set. 1874 , p. 1 . 
${ }^{18}$ ASSINATURA HONROSA. O SEXo Feminino, 14 ago. 1875, p. 2.

${ }^{19}$ Barbara Figueiredo SOUTO, 2013 , p. 71.

${ }^{20}$ Mulheres que escreveram n'O Sexo Feminino, além das supracitadas: Ernestina Fagundes Varella, Candida A. dos Santos, Laura Eulina G., Luiza E. Pereira, Majoles, Anna Ely, Maria Leonilda Carneiro de Mendonça, I. de B. Leite, Ignez Flacia d'Aguiar Mourão, Marcolina Higgis, Maria Deraisme, Maria Candida M. de Vasconcellos. Maria Joaquina de Mesquita e Rocha, Leopoldina de J. Paes Mamede, Anna Maria Ribeiro de Sá, Marianna C. de Arantes, Maria Peregrina de Souza, Palmyra de Abreu, Eulalia Diniz, Josefa Esteves de G. Del Canto (SOUTO, 2013, p. 71).

${ }^{21}$ Até o número 4 constava o nome apenas como Amelia Carolina da Silva, talvez seu nome de solteira.

${ }^{22}$ ECHO DAS DAMAS, n. 3, 26 maio

1879 , p. 1.
Por meio de suas palavras, é possível dimensionar a extensão da divulgação do periódico pelo território nacional e em alguns outros países do rol dos considerados civilizados.

Dentre os assinantes "ilustres", Francisca Diniz ressaltou a figura do Imperador. Em sua perspectiva, ao tomar a assinatura da folha, ele demonstrara ser "dedicado protetor das letras", e ela "beija agradecida e cheia de reconhecimento as mãos de S. M. I. a quem de ora em diante será enviado este hebdomadário". ${ }^{18}$ Cabe destacar, aqui, a simpatia já existente para com o regime monárquico por parte da redatora.

As seguintes seções compunham O Sexo Feminino, porém não de modo constante, e algumas apareceram poucas vezes: "O Sexo Feminino", editorial; "Colaboração", só existente em Campanha; "Literatura"; "Noticiário"; "Avisos"; "Anúncios", apenas em uma edição em Campanha, no Rio de Janeiro sempre, onde eram anunciados geleia, colégios, jornais, modista, todos com textos muito sintéticos e ocupando um pequeno espaço da publicação; "Teatro"; "Folhetim"; "Variedades"; "Poesia"; "Literatura", "Moral Social"; "Religião"; "Transcrição"; "Moral Religiosa". Sem seção com nome específico, o jornal publicava cartas de leitores. Já, quando mudou o nome para O Quinze de Novembro do Sexo Feminino, apresentou essas seções: "O Quinze de Novembro", editorial; "O Casamento"; "Poesias"; "Imprensa"; "Anúncios".

De acordo com Barbara Figueiredo Souto, ${ }^{19}$ Francisca Diniz "[...] conseguiu conquistar um número significativo de colaboradoras". Importante destacar que suas filhas, Elisa, Albertina e Amelia Diniz, participaram ativamente da publicação, e, a partir de 1889, passou a constar no cabeçalho: "Colaboradoras - suas filhas e diversas senhoras". No seu quadro de colaboradoras, estavam mulheres que também escreveram nos outros periódicos aqui estudados, como Narciza Amalia e Maria Clara Vilhena, ambas publicaram no Echo das Damas. ${ }^{20}$

O Echo das Damas foi fundado por Amelia Carolina da Silva Couto, ${ }^{21}$ que além de proprietária era redatora da folha. O primeiro número saiu em quatro de julho de 1879 , constam no acerco da Biblioteca Nacional 12 edições, sendo a última de 28 de agosto de 1888 (de número 55). A despeito de a série documental não estar completa, é possível, por meio da análise das edições disponíveis, traçar o perfil analítico da publicação.

O jornal estava dividido em três colunas, conforme é possível observar na Imagem II, ${ }^{22}$ e possuía quatro páginas. A partir de 1880 , ele passou a apresentar quatro colunas. 
Imagem II: Primeira página da edição 3 do Echo das Damas, 26 de maio de 1879 (Acervo da Fundação Biblioteca Nacional - Brasil).

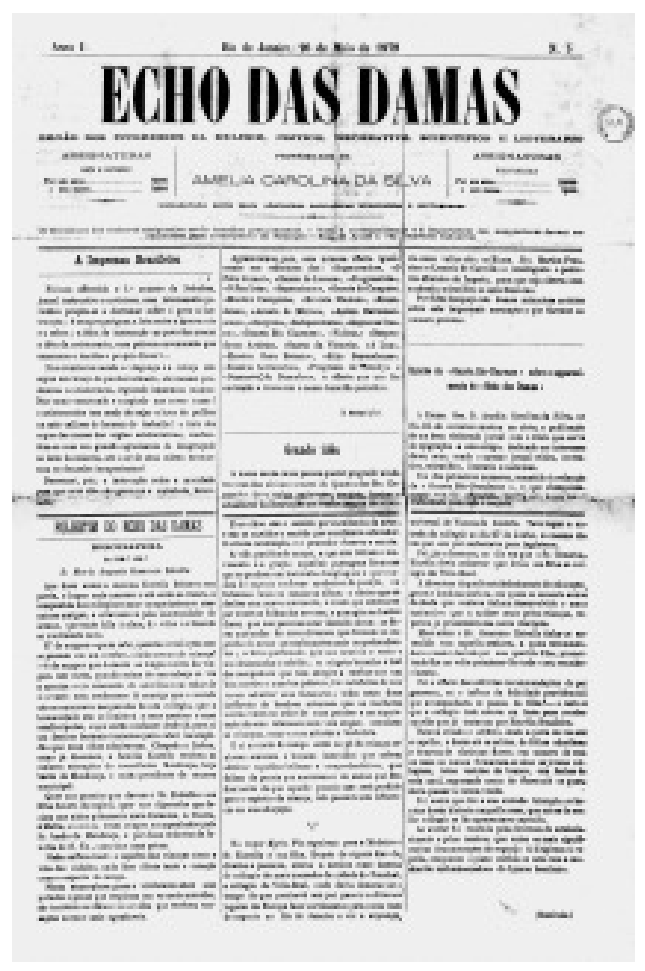

A palavra eco, no título da folha, sugere que, assim como no caso do som, os textos publicados nesse periódico precisavam ser propagados e repetidos, "algo capaz de manter no ar, mesmo nos dias seguintes, sua sonoridade

${ }^{23}$ Maria Clementina Pereira da CUNHA, 2001, p. 13. Ao estudar o carnaval na virada para o século XX, Maria Clementina da Cunha, verificou que "muitas charges colunas e crônicas carnavalescas traziam com significativa frequência, no título ou nos textos, a palavra ecos" (CUNHA, 2001, p. 13). Isto indica que o vocábulo, no título do jornal aqui estudado, estava em sintonia com determinada tendência da imprensa no emprego do mesmo. original, digna de ser lembrada aos leitores". ${ }^{23}$ Assim, as propostas defendidas pelas mulheres que escreviam no jornal deveriam ressoar na sociedade de modo mais amplo.

Até o número 3, o Echo das Damas tinha como subtítulo "Órgão dedicado aos interesses da mulher - Crítico, recreativo, científico, literário e noticioso", a partir de então, passou a constar apenas "Órgão dos interesses, da mulher, científico e literário". Com relação à palavra "recreativo", é possível que tenha sido retirada no intuito de fornecer maior credibilidade ao jornal, sugerindo que os textos publicados não consistiam apenas em lazer ou distração, mas mereceriam atenção especial por sua importância.

A fim de proporcionar maior legitimidade à folha, logo no seu cabeçalho destacava-se a competência e 
24 Muito atuante na imprensa portuguesa, Maria Amalia Vaz de Carvalho foi uma "intelectual das mais encomiadas, das que maior impacte e adesão teve entre os intelectuais e leitores desta geração e das seguintes. [...] Os seus textos nada têm de novo: reiteram questões ligadas à instrução e educação, ao combate da inércia e da passividade feminina, ao doentio e excessivo culto da moda, à luta contra a futilidade e a inutilidade, ao culto das virtudes." (Ana Maria Costa LOPES, 2005, p. 572).

25 As tipografias nas quais foi impresso o Echo das Damas foram: Imprensa Industrial, na R. da Ajuda, 75 (1879, n. 1-3); Tipografia Cosmopolita, R. do Regente, 31 (1879, n. 4); Tipografia Echo das Damas, R. do Hospício, 107 (1880); Tipografia R. de S. José, (1888, n. 49-52); Tipografia R. de S. Pedro, 109 (1888, n. 53-55). Já o escritório esteve nos seguintes endereços: R. da Ajuda, 75 (1879, distinção das mulheres que escreveriam: "Colaborado pelas mais abalizadas escritoras brasileiras e portuguesas". Com relação à colaboração portuguesa, certamente estava se referindo à Maria Amalia Vaz de Cabral, ${ }^{24}$ que escreveu em várias edições. Em 1888, esses dizeres foram extraídos e, no local, os nomes das colaboradoras passaram a ser arrolados: Emiliana de Moraes, Analia Franco, Maria Zalina Rolin, Ignez Sabino, Marie Vicent, Atilia Bastos, Adelia Barros, Mathilde Macedo, Emiliana Cortez, Maria José Canuto, Maria Amalia Vaz de Carvalho, Narciza Amalia.

Os endereços da tipografia, onde era impresso o Echo das Damas, e do escritório da redação, para o qual as correspondências deveriam ser dirigidas, mudaram várias vezes. ${ }^{25}$ Isso pode indicar a dificuldade, talvez financeira, em permanecer vinculado a uma única tipografia, ou à própria competição de mercado e a busca por tipografias mais baratas, visto que as várias mudanças também marcaram outros órgãos de imprensa. Cabe destacar que, em 1880, o jornal passou a ter sua própria tipografia, porém, posteriormente voltou a utilizar outras tipografias.

Com relação aos valores das assinaturas, observase o seguinte (Tabela 1):

Tabela 1: Valores das assinaturas do Echo das Damas (1879-1888).

\begin{tabular}{c|c|c|c|c|c}
\hline \multicolumn{6}{c}{ Corte e Niterói } \\
\hline \multirow{2}{*}{ Ano } & \multirow{2}{*}{ Números } & \multicolumn{5}{c}{ Tipo de Assinatura } \\
\cline { 3 - 6 } & & Anual & Semestral & Trimestral & Mensal \\
\hline \multirow{3}{*}{1879} & 1,2 & $6 \$ 000$ & $4 \$ 000$ & - & - \\
\cline { 2 - 6 } & 3 & $8 \$ 000$ & $5 \$ 000$ & - & - \\
\cline { 2 - 6 } & 4 & - & - & $3 \$ 000$ & $1 \$ 000$ \\
\hline 1880 & 6 & $10 \$ 000$ & $6 \$ 000$ & - & - \\
\hline 1888 & $49-55$ & $10 \$ 000$ & - & - & - \\
\hline \multirow{2}{*}{ Ano } & \multirow{6}{*}{ Números } & \multicolumn{5}{|c}{ Provincias } & Tipo de Assinatura \\
\cline { 2 - 6 } & 1,2 & Anual & Semestral & Trimestral & Mensal \\
\hline \multirow{3}{*}{1879} & 3 & $12 \$ 000$ & $7 \$ 000$ & - & - \\
\cline { 2 - 6 } & 4 & $12 \$ 000$ & $7 \$ 000$ & - & - \\
\cline { 2 - 6 } & 6 & $12 \$ 000$ & - & - & - \\
\hline 1880 & $49-55$ & $12 \$ 000$ & - & - & - \\
\hline 1888 & &
\end{tabular}

Fonte: Echo das Damas (1879-1888).

Ao analisar os preços das assinaturas, pode-se inferir que, dada as variações presentes, nos primeiros números, o jornal ainda não havia delimitado o melhor montante para 
n. 1-3), no mesmo local da tipografia; R. da Ajuda, 155 (1879, n. 4); R. do Hospício, 197 (1880); R. S. José, 99 (1888, n. 49-53); S. Pedro, 109 (1888, n. 54-55); os dois últimos junto com a tipografia. atrair assinantes. Em 1879, para a Corte e Niterói, o valor das assinaturas anual e semestral teve aumento no número 3 . Entretanto, essa estratégia não foi exitosa, pois na edição seguinte não mais foi oferecida a possibilidade de assinaturas anual e semestral, somente trimestral e mensal, sugerindo que talvez os leitores não quisessem arriscar em investir em um jornal que poderia não durar um semestre, quiçá um ano. Após 1880, constata-se uma manutenção no valor das assinaturas que, em 1888, passam a ser apenas anual. No caso das assinaturas para as outras Províncias, não se observa tantas variações, talvez porque não fossem esses os assinantes que mantinham a folha, mas sim aqueles que residiam no mesmo local onde ela era editada, ou porque os de fora do Rio de Janeiro assinariam a folha independemente do preço. A estabilidade no valor e nas modalidades das assinaturas, na década de 1880, também pode indicar que o Echo das Damas já havia conseguido uma quantidade suficiente de assinantes.

Em 1888, o Echo das Damas publicou, sob o título de "Álbum de Ouro", a lista de todos os seus assinantes, que, naquele momento, perfaziam 272. Dentre os quais estavam a Princesa Regente; muitos nomeados como doutores, supostamente médicos; companhias diversas; etc. (ver Tabela 2).

Tabela 2: Perfil dos assinantes do Echo das Damas em 1888.

\begin{tabular}{lcc}
\hline Categoria & Quantidade & Porcentagem (\%) \\
\hline Doutores & 65 & 23,9 \\
Mulheres & 39 & 14,3 \\
Companhias & 17 & 6,3 \\
Comendadores & 12 & 4,4 \\
Portadores de títulos nobiliárquicos & 10 & 3,7 \\
Conselheiros & 9 & 3,3 \\
Militares & 8 & 2,9 \\
Deputados & 7 & 2,6 \\
Outros & 105 & 38,6 \\
Total & $\mathbf{2 7 2}$ & $\mathbf{1 0 0 , 0}$ \\
\hline
\end{tabular}

Fonte: Echo das Damas, 4 jan. 1888, 10 jan. 1888, 31 jan. 1888 e 4 mar. 1888.

No tocante à periodicidade, ela foi muito variável. Em 1888, a folha pretendia sair diariamente: "Conforme já noticiamos, pretendemos passar a diária a publicação do Echo das Damas". ${ }^{26}$ Entretanto, o desejo se concretizou.

O jornal estava dividido em algumas seções, as quais ${ }^{26}$ ECHO DAS DAMAS, 27 maio 1888, p. 1. não eram publicadas necessariamente em todas as edições: "Echo das Damas", editorial; "Folhetim Echo das 
27 Nasceu no Recife, em 1851 , onde viveu até seus 26 anos, era prima do poeta Álvares de Azevedo (TEIXEIRA, 2010, p. 62).

${ }^{28}$ A edição de lançamento, publicada em São Paulo, foi de 18 de abril de 1888 e a última de 23 de fevereiro de 1889, totalizando 13 números. No Rio de Janeiro, o primeiro número data de 02 de março de 1889, indicando a não interrupção na periodicidade durante a mudança do local de publicação. A última edição existente no acervo da Biblioteca Nacional é de 28 de outubro de 1894 .

${ }^{29}$ Em São Paulo, a folha foi impressa na Tipografia União, situada no Largo 7 de Setembro (n. 1-23), já os escritórios situaram-se na Travessa da Sé, 1 (edições: n. 1 14) e, posteriormente, juntamente com a tipografia (n. 15- 23). No Rio de Janeiro, os endereços dos escritórios foram: $R$. do Rezende 146 (n. 24-29); R. do Senado, 45 (n. 31-83); R. do Senado, 43 (n 84-85), pode ser que tenha ocorrido um erro de impressão e ainda fosse no mesmo endereço anterior, ou seja, no número 45 daquela rua, a mesma observação vale para o caso da tipografia nesses números; R. da Ajuda, 10 (n. 86-87); R. da Quitanda, 1 (n 101-132); Travessa das Saudades 32, (n. 139-159); R. da Alfândega, 198, na tipografia Confiança (n 160-164); R. D. Feliciana, 195 (n. 165-167); R. da Alfândega, 198 (n. 168-177). As tipografias utilizadas pelo jornal na capital fluminense foram as seguintes: R. da Alfândega, 215 (n. 23-26); R. do Rezende, 146 (n. 27-29); Tipografia d'A Familia (n. 32-60); R. do Senado, 45 (n. 61-83); R. do Senado, 43 (n. 84-85); R. da Ajuda 10, (n. 86-87); Tipografia d'A Familia (n. 96-99); Tipografia da Companhia Imprensa Familiar, R. da Quitanda, 1 (n. 100-132); Tipografia d'A Familia (n. 139). 30 O capital da Companhia era de 50:000\$000, sendo divido em ações de $100 \$ 000$ réis (A Familia 02/04/1891). A diretoria da Companhia era composta pelas seguintes pessoas, exercendo os respectivos cargos: Ignez Sabino, presidente:
Damas"; "Noticiário"; "Colaboração", textos das colaboradoras; "Distração"; "Poesias"; Anedotas; "Variedades"; "Teatros"; "Receitas Úteis", dicas domésticas; "Miudezas"; "Indicador", posteriormente "Almanack", publicava endereços de médicos e dentistas; e "Anúncios". Além de artigos não vinculados a uma seção em específico. A partir de 1888, o periódico apresentou poucas seções. Nos "Anúncios", havia a propaganda de artigos variados: luvas, tecidos, pianos, tranças, jornais, colégios, perfumes finos, café, fantasias, marcenarias, fábrica de cerveja, vinhos, elixir, mata formigas, loja de armas, externatos, jardins de crianças, papelaria, máquinas de costura, confeitaria, leite, modista. Ao analisar a diversidade de anúncios, é possível verificar que a maioria estava relacionada a artigos supostamente de interesses ditos femininos.

Mudando o foco para o jornal A Familia (1888-1894), ele teve como proprietária, diretora e redatora-chefe a pernambucana Josephina Álvares de Azevedo, que também assinava seus artigos como Zefa. ${ }^{27}$ De periodicidade semanal, inicialmente fora publicado em São Paulo, mas, com a mudança de sua proprietária e redatora, passou a ser editado na cidade do Rio Janeiro, ${ }^{28}$ onde o continuou a ser produzido seguindo os mesmos padrões de formatação e de temática anteriores, inclusive, continuando a numeração. Assim como os outros jornais, A Familia teve diferenciados endereços de escritório e tipografia ao longo dos anos. ${ }^{29}$

Josephina de Azevedo se manteve como proprietária até março de 1891, quando a publicação passou a pertencer a uma sociedade anônima, a "Companhia Imprensa Familiar". ${ }^{30}$ A redatora afirmou que, embora tivesse "um capital mais que suficientemente rendoso para dispensar-me de recorrer a uma transação mercantil", faltava, entretanto,

[...] elementos pecuniários para dar ao meu jornal o desenvolvimento compatível com as ideias adiantadas do tempo e mais ainda para dar maior impulso à propaganda que constitui o meu lema de combate a emancipação feminina - e entendi que era chegada a ocasião de sacrificar em holocausto às ideias que defendo os meus naturais escrúpulos socorrendo-me da agremiação de capitais alheios para completa realização da mais ardente e justa aspiração: a cooperação da mulher brasileira em todas as manifestações da atividade social. ${ }^{31}$

Portanto, nas palavras de Josephina de Azevedo, a alteração de propriedade não era por falta de dinheiro para manter a publicação, mas pela possibilidade de, com capital maior, poder aumentar os investimentos no jornal. A despeito disso, Josephina de Azevedo continuou a exercer as funções de diretora e redatora. 
F. de Assis Vieira, secretário; José de Araujo Couto, gerente e tesoureiro; Josephina Alvares de Azevedo, redatora-chefe; Tenente José Augusto Vinhaes, presidente do Banco Operário e representante do Congresso Nacional, Comendador José Manoel Teixeira e Dr. Victor M. de S. Monteiro, diretor e secretário do Banco dos Operários conselho fiscal; e Firmino Julio Ribeiro, subgerente (A Familia, 25 abr. 1891).

31 AZEVEDO, Josephina de. A Familia, 2 abr. 1891, p. 2.

32 NOVO FORMATO. A Familia, 24 maio 1890 , P. 1.

${ }^{33}$ A REDATORA. A Familia, $26 \mathrm{fev}$. 1888.

${ }^{34}$ A FAMILIA, 18 nov. 1888, p. 1.

${ }^{35}$ Ana Luiza MARTINS, 2008, p. 43.
Com relação aos valores das assinaturas anuais, não se observa grandes mudanças, elas variaram de $10 \$ 000$ a $12 \$ 000$ para a capital, e $12 \$ 000$ a $14 \$ 000$ para o interior, ou províncias (ambos os termos foram empregados). Em 1890, entre as edições de número 61 e 87, A Familia sofreu alteração de formato e teve seus valores de assinaturas reduzidos, no caso da Corte, de $12 \$ 000$ (anual) para $10 \$ 000$ (anual) e $6 \$ 000$ (semestral); e para as outras Províncias, de $15 \$ 000$ (anual) para $12 \$ 000$ (anual) e $7 \$ 000$ (semestral).

Na maioria dos números, A Familia foi impressa em oito páginas, nas quais os textos estavam dispostos em três colunas, ver Imagem III. Foram poucos números nos quais apresentou quatro páginas ou mais colunas (quatro ou cinco). Em 1890, porém, seu formato foi mudado, conforme constatase nesta publicação: "Graças ao desenvolvimento que está tendo a nossa pequena folha, julgamos poder ir desde já modificando-a, no sentido de dar-lhe maior impulso, como convém [...] começamos por mudar o formato da revista para o de jornal" ${ }^{32}$ Todavia, essa nova formatação não perdurou e, no ano seguinte, voltou ao padrão original. Segundo a redatora, o retorno foi consequência de pedidos dos leitores:

De certo, vai a leitora surpreender-se hoje com a inesperada volta d'A Familia ao formato de revista. É que a prática veio trazer-nos a convicção de que é esse o formato mais conveniente a um [sic] publicação deste gênero. Muitas pessoas há que colecionam esta folha, e para estas a revista é sem dúvida muito mais cômoda: tanto assim é que reiteradas tem sido as solicitações para a mudança feita. ${ }^{33}$

Destaco aqui que, apesar dessas mudanças, me refiro ao periódico como jornal, pois este termo foi empregado pela própria publicação. No primeiro número, por exemplo, constava o subtítulo "Jornal literário dedicado à educação da mãe de família". ${ }^{34}$ Nesta mesma edição de lançamento, ambos os termos, jornal e revista, foram empregados por Josephina Alvares de Azevedo em seu editorial. Nesse sentido, Ana Luiza Martins, em seu estudo sobre as revistas na virada para o século XX, destaca: "Defini-la como gênero de impresso esbarra nas fronteiras quase conjugadas às do jornal, periódico que lhe deu origem e do qual, no passado, se aproximava tanto na forma - folhas soltas e in folio - como, por vezes, na disposição do conteúdo, isto é, seções semelhantes". ${ }^{35}$

Diferente dos outros jornais aqui analisados, A Familia foi o único a apresentar ilustrações, talvez reforçando a sua configuração de revista. Consoante Martins,

No curso da trajetória da revista, contudo, um marco na imprensa da época: os recursos da ilustração. [...] 
${ }^{36}$ MARTINS, 2008, p. 40. enriquecendo ainda mais aquelas atraentes publicações, transformadas em objetos atraentes, acessíveis até mesmo ao público menos afeito à leitura, se não à população analfabeta, que recebia as mensagens através dos desenhos grafados de forma visualmente inteligível. ${ }^{36}$

Foram publicadas imagens de pessoas biografadas no semanário e de algumas paisagens sobre as quais o artigo tratava.

Imagem III: Primeira página do número 24 de $A$ Familia, 18 de maio de 1889, primeira edição publicada na cidade do Rio de Janeiro (Acervo da Fundação Biblioteca Nacional - Brasil)

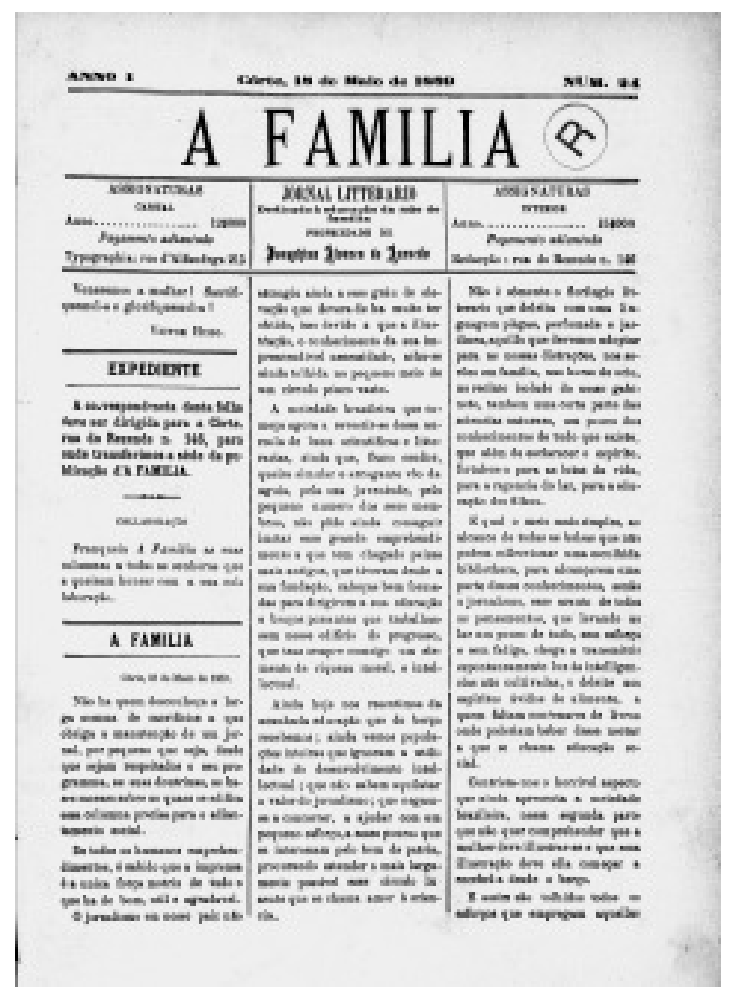

A Familia, no correr dos anos, apresentou as seguintes seções, que não eram publicadas de modo constante: "Expediente"; "A Família"; "Novidades"; "Como nos tratam", na qual se publicava a repercussão do periódico na imprensa; "Seção Alegre"; "Receitas Domésticas", com dicas de remédios, culinária, cosméticos, etc.; "Teatros", existente quando a publicação se transferiu para o Rio de Janeiro; 
${ }^{37}$ ANÚNCIOS FIXOS. A Familia, 1894, p. 1.

${ }^{38}$ SOUTO, 2013, p. 115.

${ }^{39}$ AZEVEDO, Josephina de. A Familia, 2 abr. 1891, p. 2.
"Indicador", com endereços de médicos, dentistas, advogados e cartomantes; "Livros e jornais", "Necrologia"; e "Anúncios". Com relação a esta última, alguns dos produtos/ empresas anunciados foram: sapólio, fábrica de cerveja, modista, loja de fantasias, sorvetes, água mineral, fotografia, pianos, armazéns, chapéus, fazendas e armarinhos, elixir, louças, confeitaria, xarope, camisaria, bancos. Nos últimos números de 1892, a quantidade de anúncios cresceu, de uma página passou a ocupar de três a quatro. É possível o aumento estar relacionado a alguma dificuldade financeira do periódico, que para saná-la resolveu abrir mais espaço aos anunciantes. Importante sublinhar que, nesse momento, foi anunciada uma quantidade significativa de produtos/ empresas de outros estados, por exemplo, de São Paulo (capital, Campinas, Taubaté, Iguape, Araraquara, Santos, Jaguarí, Piracicaba, Rio Claro, Ribeirão Preto, Campo de Marte); Minas Gerais (Juiz de Fora, Santa Luzia do Cataguazes, Poços de Caldas, São João Del Rei, São Paulo de Muriaé, Santa Rita de Caldas, Teixeiras, Cataguazes, Varginha); Espírito Santo (Vitória); Pará e Pernambuco.

Em muitas dessas cidades fora do Rio de Janeiro, havia assinantes, sendo muitos dos quais também anunciantes. Em 1894, existia um desconto na assinatura para anunciantes,

Para as casas e pessoas que anunciam constantemente e aos quais possa convir a publicação de seus anúncios em nossa revista, resolvemos abrir assinaturas em que seja considerada a diferença de preços entre os simples assinantes e aqueles que façam publicações: sendo portanto a diferença para mais arbitrada conforme 0 tamanho do anúncio a fazer. ${ }^{37}$

Essa ampla divulgação pelo território nacional de $A$ Familia resultava do empenho de Josephina de Azevedo. A redatora viajou o litoral brasileiro, de Norte a Sul, fazendo propaganda de seu periódico, conforme destaca Souto, "[...] a redatora não poupou forças para fazer seu jornal circular entre os anos de 1888 e 1894, com êxito". ${ }^{38}$

Naquele mesmo ano, 1894, o jornal publicou seu "Livro de Ouro", com a listagem dos assinantes. Infelizmente, no acervo da Biblioteca Nacional, a última edição disponível é de número 177, na qual, ao término da lista, foi assim destacado: "continua" nos números seguintes, informando que a listagem ainda seria complementada. Embora não seja o arrolamento completo, é possível traçar o perfil dos assinantes de A Familia (Tabela 3). Importante destacar que, em 1891, ou seja, três anos antes de a lista ser editada, Josephina Azevedo afirmou que o periódico contava com "cerca de 2.000 assinantes". ${ }^{39}$ 
Tabela 3: Perfil dos assinantes de A Familia em 1894.

\begin{tabular}{lcc}
\hline \multicolumn{1}{c}{ Categoria } & Quantidade & Porcentagem (\%) \\
\hline Militares & 38 & 28,5 \\
Companhias & 37 & 27,8 \\
Doutores & 12 & 9,0 \\
Mulheres & 11 & 8,3 \\
Deputado & 1 & 0,8 \\
Comendador & 1 & 0,8 \\
Portador de título nobiliárquico & 1 & 0,8 \\
Outros & 32 & 24,0 \\
Total & $\mathbf{1 3 3}$ & $\mathbf{1 0 0 , 0}$ \\
\hline
\end{tabular}

Fonte: A Familia, 4 mar. 1894, 22 mar. 1894, 29 abr. 1894 e 28 out. 1894.

${ }^{40}$ Isabel de Mattos Dillon, cirurgiã dentista; Analia Franco, professora da cidade de Taubaté Maria Zalina Rolim; Adelia Barros: Felicidade de Macedo; Maria Amelia de Queiroz, do Recife: Emiliana de Moraes, esposa do Dr. Pedro de Moraes, de Ubá; Maria Zalina Rolin, filha do Juiz de Direito Sr. Roque; Maria Ramos, professora da cidade paulista de Mogi das Cruzes; Maria Augusta, diretora de Colégio em Juiz de Fora; Luiza Thienpont, professora da estação de mineiros; Paulina A. da Silva, esposa de Santos Silva, residente na capital de São Paulo; Alzira Rodriguez, do Rio de Janeiro diretora do Colégio Piracicabano em Piracicaba, interior de São Paulo; Ignez Sabino Pinho Maia Mlle. Rennotte; Carmem Freire, Baronesa de Mamanguape Mariana da Silveira; Adelaide Peixoto; Julia Cortines; Maria Clara Vilhena da Cunha; Presciliana Duarte; Maria Jorandes; Octavia Mullulo e Perpetua do Valle (TEIXEIRA, 2010, p. 59).

${ }^{41}$ TEIXEIRA, 2010 , p. 61.

${ }^{42}$ A Familia, 25 abr. 1891, p. 1.

43 Fernanda Alina de Almeida ANDRADE, 2006, p. 48
Ao observar as categorias de assinantes, salta aos olhos o expressivo número de militares e companhias, muitas das quais também anunciavam no jornal. Mesmo considerando que os dados representam apenas uma parcela do total de assinantes, ao se fazer uma análise comparativa dos valores relativos, verifica-se que a quantidade de mulheres assinantes d'A Familia era ligeiramente menor (8,3\%) que a do Echo das Damas (14,3\%).

Com relação ao seu quadro de colaboradoras, ${ }^{40} \mathrm{O}$ semanário contava com muitas professoras e, segundo Teixeira, "Cada uma delas escrevia de acordo com a sua vivência, ou seja, as que atuavam como professoras redigiam artigos focando a educação da mulher". ${ }^{41}$ Algumas delas também publicaram no Echo das Damas, nomeadamente, Analia Franco, Maria Zalina Rolim, Adelia Barros, Emiliana de Moraes e Ignez Sabino Pinho Maia. O jornal também tinha uma colaboradora e representante em Paris: Mme. Potonié Pierre. ${ }^{42}$

Sobre os objetivos dos três jornais, além de produzidos e direcionados às mulheres, suas propostas vinculavam-se aos chamados interesses da mulher, sobretudo no tocante à educação. Logo em sua primeira página, O Sexo Feminino trazia estampado os dizeres: "É pelo intermédio da mulher que a natureza escreve no coração do homem". A frase fora extraída do livro Educação das mães de família ou $A$ civilização do gênero humano, de Aime Martin, obra premiada pela Academia Francesa, em 1840, e traduzida para o português em 1870. Segundo Fernanda Alina de Almeida Andrade, a citação já evidenciava o mote principal da redatora, Francisca Senhorinha da Motta Diniz, qual seja: "o aperfeiçoamento da sociedade brasileira através da educação da mulher". ${ }^{43}$

De acordo com Kelly Cristina Nascimento, O Sexo Feminino foi o precursor, na imprensa periódica brasileira, 
${ }^{44}$ Kelly Cristina NASCIMENTO, 2006, p. 65.

${ }^{45}$ O Sexo Feminino, 23 maio 1874, p. 1.

${ }^{46}$ A RACIONAL EMANCIPAÇÃO DA MULHER. O Sexo Feminino, 22 jul. 1875 , p. 2.

${ }^{47}$ A EDUCAÇÃO DA MULHER. O Sexo Feminino, 7 set. 1873 , p. 1 , grifos do original.

${ }^{48}$ A EDUCAÇÃO DA MULHER. O Sexo Feminino, 7 set. 1873, p. 1 . ${ }^{49} \mathrm{~A}$ RACIONAL EMANCIPAÇÃO DA MULHER. O Sexo Feminino, 22 jul. 1875 , p. 1.

${ }^{50}$ NASCIMENTO e OLIVEIRA, 2007, p. 431.

51 COUTO, Amelia Carolina da Silva. Echo das Damas, 18 abr. 1879, p. 1. da defesa da emancipação da mulher. A autora assevera que o periódico apresentava a mulher como essencial para o progresso do país: "A confiança de Francisca Senhorinha na força da educação estava estreitamente relacionada com a sua crença no progresso". ${ }^{44} \mathrm{Na}$ concepção da redatora d'O Sexo Feminino, publicar aquele jornal era uma espécie de missão civilizadora, pois buscava promover a educação feminina que, por sua vez, colaboraria para o progresso da nação, posto ser aquele um "hebdomadário quase que exclusivamente dedicado à educação, instrução e emancipação da mulher". ${ }^{45}$

Para a redatora, "[...] não haverá progresso possível na moral do gênero humano, enquanto não se convencerem, os mesmos, da necessidade da educação das mães de família". ${ }^{46}$ Assim, defendia que os pais de família ensinassem suas filhas

[...] a ler, escrever, contar, gramática da língua nacional perfeitamente, e depois, economia e medicina doméstica, a puericultura, a literatura (ao menos a nacional e portuguesa), a filosofia, a história, a geografia, a física, a química, a história natural, para coroar esses estudos a instrução moral e religiosa. ${ }^{47}$

Com esses saberes a mulher não ficaria dependente economicamente do pai, marido ou irmão, pois "A riqueza intelectual produzirá o dinheiro, e com este se satisfarão as necessidades". ${ }^{48}$ Francisca Diniz defendia a "tríplice educação: Física, moral e intelectual" ${ }^{49}$

Sobre a campanha emancipacionista empreendida pelo O Sexo Feminino, Cecília Vieira do Nascimento e Bernardo J. Oliveira afirmam que as mulheres que utilizavam a imprensa para lutar por melhores condições de vida "[...] estavam impulsionadas por um amplo movimento de redefinição da mulher na modernidade e vinham a utilizarse do meio impresso como espaço para suas várias reivindicações" (2007, p. 431)..$^{50}$ Os autores destacam a atuação do periódico na defesa do voto e instrução femininos, bem como a campanha realizada em prol do casamento civil. Com relação a este, cabe sublinhar que era uma temática também discutida em outros setores da sociedade.

Na edição de lançamento do Echo das Damas, Amelia Carolina da Silva Couto afirmou que a publicação pretendia "Defender os interesses da mulher". Também sublinhou os benefícios da educação feminina para a nação, a "[...] folha advoga uma causa santa que deve merecer a consideração de todos aqueles que se interessam pelo progresso moral deste país [...] queremos a mulher ilustrada sob o ponto de vista humanitário". ${ }^{51}$ 
${ }^{52}$ COUTO, Amelia Carolina da Silva. "A missão da mulher". Echo das Damas, 18 abr. 1879, p. 2.

${ }^{53}$ COUTO, Amelia Carolina da Silva. "Questão religiosa". Echo das Damas, ano I, n. 6, 3 ago. 1880 , p. 1.

${ }^{54}$ A MULHER NA MEDICINA. ECho das Damas, maio 1879, p. 1-2.

55 A MULHER INGLESA NOS CARGOS PÚBLICOS. Echo das Damas, 4 jan. 1888, p. 1.
De modo semelhante ao pregado pelo O Sexo Feminino, a educação feminina era apresentada como mola propulsora para o progresso nacional:

Da educação da mulher portanto nós assim pensamos, depende a prosperidade de uma nação. Eduque-se, pois a mulher: quebrem-se de uma vez estes preconcei-tos estultos: de-se-lhes uma instrução sólida e variada e teremos bons cidadãos e uma sociedade moralizada. ${ }^{52}$

Caso o contrário, "Desde que a mulher seja ignorante, viciosa, fanática ou supersticiosa, educará pessimamente os filhos e péssima será a sociedade em que influir eles". ${ }^{53}$ Assim, pode-se se inferir que o principal beneficiário com a educação feminina seria a sociedade, e não a mulher em si.

Além da importância da educação da mulher para que ela bem educasse seus filhos, o Echo das Damas também defendeu, por exemplo, o acesso da mulher à instrução superior. No caso dos estudos médicos, evidenciou sendo $o$

[...] preconceito que até hoje tem impedido que as mulheres exerçam a medicina, principalmente no tratamento de crianças e de moças [...] Além do tratamento das moças e das crianças, que exclusivamente devia ser reservado às mulheres formadas em medicina, julgamos que, no futuro prestam importantes serviços à humanidade como oculistas. Todos sabem que $\mathrm{o}$ tratamento das moléstias de olhos e suas operações exigem uma paciência e uma delicadeza que raríssimas vezes os homens possuem. ${ }^{54}$

Ou seja, algumas áreas da medicina teriam muito a ganhar dada à predisposição "natural" da mulher para elas. Para substanciar ainda mais seus argumentos, o jornal publicou, em seu folhetim, a biografia de Maria Augusta Generoso Estrella, primeira brasileira a se formar em medicina, tendo estudado em Nova lorque.

O Echo das Damas também mostrou ser favorável ao acesso de mulheres aos serviços públicos, se não a todos, pelo menos a alguns. Em 1888, publicou o artigo "A mulher inglesa nos cargos públicos", evidenciando que "O satisfatório êxito obtido pela prática nas repartições do correio, com o emprego da mulher no desempenho dos diferentes cargos, fez com que se utilizassem os seus serviços em outros ramos de administração pública, e induziu muitos estabelecimentos comerciais a seguir este exemplo". ${ }^{55}$ Pode-se imaginar que o objetivo de tal artigo era sugerir que isso também poderia ocorrer aqui no Brasil.

Já A Familia, logo em seu cabeçalho, trazia a seguinte frase de Victor Hugo: "Veneremos a mulher! Santifiquemo-la e 
${ }^{56}$ Karine da Rocha OLIVEIRA, 2009 ,
p. 4.

${ }^{57}$ SOUTO, 2013, p. 82.

${ }^{58} \mathrm{O}$ NOSSO FIM. A Familia, $8 \mathrm{dez}$. 1888 , p. 1.

${ }^{59}$ MUZART, 2003, p. 226

60 TEIXEIRA, 2010, p. 62.

${ }^{61}$ OLIVEIRA, 2009, p. 23.

${ }^{62}$ AZEVEDO, Josephina Alvares de A Familia, 18 nov. 1888 , p. 1. glorifiquemo-la!", indicando uma importância quase divina da mulher. A temática mais frequente na publicação foi: "educação, trabalho e voto feminino". ${ }^{56}$ Consoante Souto, "Josephina de Azevedo se lançou na imprensa com o intuito de lutar pela emancipação da mulher, tendo a igualdade e a liberdade como princípios". ${ }^{57}$ Em seu primeiro número, destacou a importância da educação feminina, "A Familia vem ocupar a posição que há longo tempo aguardava na imprensa desta província, onde há muito se fazia sentir a necessidade de um órgão que se prendesse unicamente à educação feminina". ${ }^{58}$ Acerca da defesa do sufrágio feminino, Josephina de Azevedo também escreveu a peça "O voto feminino", na qual reiterava as ideias apresentadas no periódico. ${ }^{59}$ Com relação aos artigos publicados pela proprietária-redatora, Teixeira assim destaca: "Praticamente tudo o que escreveu e publicou teve um único objetivo: intervir na ordem social e política do seu tempo de modo a criar condições mais justas e igualitárias para as mulheres". 60

O jornal contava com colaboradoras internacionais, sendo que seu "[...] objetivo não seria apenas expor suas ideias [...] seria despertar a consciência das mães paulistanas para que elas pudessem competir com os homens em todos os campos profissionais, seguindo o exemplo das francesas e inglesas". ${ }^{61}$ Ou seja, de certa maneira, havia uma sintonia entre algumas das ideias propagadas naqueles países e as veiculadas em A Familia.

Em um período no qual muitas teorias científicas e cientifizantes pregavam a inferioridade feminina, Josephina Azevedo, em A Familia, advogou a igualdade entre homens e mulheres:

Mas nós não somos a eles inferiores porque somos suas semelhantes, embora de sexo diverso. Temos, segundo a nossa natureza, funções especiais, como eles pela mesma razão as tem. Mas isso não é razão de inferioridade, porque essa traz o animal na escala natural de suas aptidões. Portanto, em tudo devemos competir com os homens - no governo da família, como na direção do estado. ${ }^{62}$

Aqui ela deixava clara a defesa que faria em todos os números da publicação, qual seja, a igualdade entre os sexos.

Por fim, ao observar os três periódicos - O Sexo Feminino, Echo das Damas e A Familia - é possível constatar que todos tinham na luta pela educação e emancipação da mulher a sua bandeira. Entretanto, a defesa da emancipação feminina presente em A Familia foi muito mais contundente que a dos outros, centrando as benesses de tal na figura da mulher em si. O Sexo Feminino e o Echo das Damas subli- 
nharam, sobretudo, os ganhos civilizacionais da nação com a educação feminina.

\section{Referências}

A EDUCAÇÃO DA MULHER. O Sexo Feminino, Rio de Janeiro, ano 1, n. 1, 7 set. 1873, p. 1.

A FAMILIA, Rio de Janeiro, ano 1, n. 1, 18 nov. 1888, p. 1.

A FAMILIA, Rio de Janeiro, ano 1, n. 94, 18 maio 1889, p. 1.

A FAMILIA, Rio de Janeiro, ano 3, n. 101, 25 abr. 1891, p. 1.

A MULHER INGLESA NOS CARGOS PÚBLICOS. Echo das Damas, Rio de Janeiro, ano 3, n. 11, 4 jan. 1888, p. 1.

A MULHER NA MEDICINA. Echo das Damas, Rio de Janeiro, ano 1, n. 2, 2 maio 1879, p. 1-2.

ANDRADE, Fernanda Alina de Almeida. Estratégias e escritos: Francisca Diniz e o movimento feminista do século XIX (1873/1890). 2006. Dissertação (Mestrado em História) Programa de Pós-Graduação em História, Faculdade de Filosofia e Ciências Humanas da UFMG, Belo Horizonte.

ANIVERSÁRIO DO PERIÓDICO. O Sexo Feminino, Rio de Janeiro, n. 145, 7 set. 1874, p. 1-2.

ANÚNCIOS FIXOS. A Familia, Rio de Janeiro, ano 4, n. 172, 15 abr. 1894, p. 1.

A RACIONAL EMANCIPAÇÃO DA MULHER. O Sexo Feminino, Rio de Janeiro, ano 3, n. 1, 22 jul. 1875, p. 1-3.

A REDATORA, A Familia, Rio de Janeiro, ano 3, n. 96, 26 fev. 1891 , p. 6.

ASSINATURA HONROSA. O Sexo Feminino, Rio de Janeiro, ano 2, n. 4, 14 ago. 1875, p. 2.

AZEVEDO, Josephina Alvares de. A Familia, Rio de Janeiro, ano 1, n. 1, 18 nov. 1888, p. 1-2.

AZEVEDO, Josephina de. "Companhia imprensa família". A Familia, Rio de Janeiro, ano 3, n. 100, 2 abr. 1891, p. 2.

BARBOSA, Marialva. História cultural da imprensa: Brasil, 1800-1900. Rio de Janeiro: Mauad X, 2010.

BICALHO, Maria Fernanda. "O Bello Sexo: imprensa e identidade feminina no Rio de Janeiro em fins do século XIXe início do século XX'. In: COSTA, Albertina de Oliveira; BRUSCHINI, Cristina (Orgs.). Rebeldia e submissão: estudos sobre a condição feminina. São Paulo: Vértice, 1989, p. 79-99.

CHARTIER, Roger. "Do livro à leitura". In: CHARTIER, Roger (Org.). Práticas de leitura. São Paulo: Estação Liberdade, 1996, p. 77-106.

COUTO, Amelia Carolina da Silva. Echo das Damas, ano 1 , n. 1, 18 abr. 1879, p. 1-2.

COUTO, Amelia Carolina da Silva. "A missão da mulher". Echo das Damas, ano 1, n. 1, 18 abr. 1879, p. 2.

COUTO, Amelia Carolina da Silva. "Questão religiosa". Echo das Damas, ano I, n. 6, 3 ago. 1880, p. 1. 
CUNHA, Maria Clementina Pereira da. Ecos da folia: uma história do carnaval carioca entre 1880 e 1920. São Paulo: Companhia das Letras, 2001.

DARNTON, Robert. O beijo de Lamourette: mídia, cultura e revolução. São Paulo: Companhia das Letras, 2010, p. 204-231.

D'INCAO, Maria Ângela. "Mulher e família burguesa". In: DEL PRIORE, Mary. História das mulheres no Brasil. 10. ed. São Paulo: Contexto, 2012, p. 223-240.

ECHO DAS DAMAS, Rio de Janeiro, ano 1, n. 3, 26 maio 1879 , p. 1.

ECHO DAS DAMAS, Rio de Janeiro, ano 3, n. 55, 27 maio 1888, p. 1.

FERREIRA, Tania Maria Bessone da Cruz. "As leitoras no Rio de Janeiro do século XIX: a difusão da literatura". Gênero, Niterói, v. 5, n. 2, p. 81-93, 2005.

GONDRA, José Gonçalves; SHUELER, Alessandra. Educação, poder e sociedade no Império brasileiro. São Paulo: Cortez, 2008.

JINZENJI, Mônica Yumi. Cultura impressa e educação da mulher no século XIX. Belo Horizonte: Editora UFMG, 2010.

HALLEWELL, Laurence. O livro no Brasil: sua história. 3. ed. São Paulo: Edusp, 2012.

LOPES, Ana Maria Costa. Imagens da mulher na imprensa feminina de Oitocentos: percursos de modernidade. Lisboa: Quimera, 2005.

MARTINS, Ana Luiza. Revistas em revista: imprensa e práticas culturais em tempos de República, São Paulo (18901922). São Paulo: Edusp: Fapesp, 2008.

MUZART, Zahidé Lupinacci. "Uma espiada na imprensa das mulheres no século XIX". Revista Estudos Feministas, Florianópolis, v. 11, n. 1, p. 225-233, jan./jun. 2003.

NASCIMENTO, Cecília Vieira do; OLIVEIRA, Bernardo J. "O Sexo Feminino em campanha pela emancipação da mulher". Cadernos Pagu, n. 29, p. 429-457, jul./dez. 2007.

NASCIMENTO, Kelly Cristina. Entre a mulher ideal e a mulher moderna: representações femininas na imprensa mineira - 1873-1932. 2006. Dissertação (Mestrado em História) - Programa de Pós-Graduação em História, Faculdade de Filosofia e Ciências Humanas da UFMG, Belo Horizonte.

NOVO FORMATO. A Familia, Rio de Janeiro, ano 2, n. 61, 24 maio 1890, p.1.

OLIVEIRA, Karine da Rocha. Josephina Álvares de Azevedo: a voz feminina no século XIX através das páginas do jornal A Família. Rio de Janeiro: Fundação Biblioteca Nacional, Programa Nacional de Apoio à Pesquisa, 2009. Disponível em: <http://www.bn.br/portal/arquivos/pdf/ Karine_da_Rocha.pdf >. Acesso: 8 ago. 2014. 
O NOSSO FIM. A Familia, ano I, n. 2, 8 dez. 1888, p. 1.

O QUINZE DE NOVEMBRO DO SEXO FEMININO, Rio de Janeiro, ano III, n. 14, 16 abr. 1890, p. 1.

O SEXO FEMININO, Rio de Janeiro, ano 2, n. 1, 7 set. 1873, p. 4.

O SEXO FEMININO, Rio de Janeiro, ano 1, n. 33, 23 maio 1874, p. 1-3.

O SEXO FEMININO, Rio de Janeiro, ano 2, n. 1, 22 jul. 1875, p. 1.

O SEXO FEMININO, Rio de Janeiro, ano 2, n. 22, 2 abr. 1876, p. 1.

TEIXEIRA, Roberta Guimarães. Na penna da imprensa professoras e professores primários do século XIX (18521888): contribuições aos estudos da feminização do magistério. 2010. Dissertação (Mestrado em Educação) - Programa de Pós-Graduação em Educação, Centro de Ciências Humanas e Sociais da UNIRIO, Rio de Janeiro.

SOUTO, Bárbara Figueiredo. "Senhoras do seu destino": Francisca Senhorinha da Motta Diniz e Josephina Alvares de Azevedo - projetos de emancipação feminista na imprensa brasileira (1873-1894). 2013. Dissertação (Mestrado em História Social) - Programa de PósGraduação em História Social, Faculdade de Filosofia, Letras e Ciências Humanas da USP, São Paulo.

[Recebido em 11 de agosto de 2014 e aceito para publicação em 15 de junho de 2015]

The Feminine Press in the Rio de Janeiro in the Final Decades of 19th Century

Abstract: The objective of this article is to present and analyze three newspapers written by women, which circulated in the city of Rio de Janeiro at the end of the nineteenth century: O Sexo Feminino (1873-1889) - which, after the Republic, was renamed O Quinze de Novembro do Sexo Feminino (1889-1890); Echo das Damas (1879-1888) and A Familia (1888-1894). O Sexo Feminino defended mainly that women's education was necessary for the betterment of society. In Echo das Damas the main theme was the defense of women's education. Yet in A Familia, the most frequent themes were education, labor and women's suffrage. That said, I will initially present the three publications: materiality, periodicity, sections, collaborators, main themes approached, etc. Then, I will focus on the main proposals presented by these newspapers.

Key Words: Press; Women; Feminine Education.

\section{Errata}

No artigo "A imprensa feminina nas décadas finais do século XIX", com número de DOI: http://dx.doi.org/10.1590/1805-9584-2016v24n1p261, publicado na Revista Estudos Feministas, volume 24(1): http://www.scielo.br/scielo.php?script=sci_arttext\&pid=S0104026X2016000100261 \&lng=en\&nrm=iso\&tlng=pt, na nota de rodapé $n^{\circ} 52$, onde se lia:

52 O. Echo das Damas, 18 abr. 1879, p.2.

Leia-se

52 COUTO, Amelia Carolina da Silva. Echo das Damas, 18 abr. 1879, p.2. 